University of Nebraska - Lincoln

DigitalCommons@University of Nebraska - Lincoln

Educational Psychology Papers and

Publications

Educational Psychology, Department of

2006

\title{
Use of policy, education, and enforcement to reduce binge drinking among university students: The NU Directions project
}

\author{
Ian Newman \\ University of Nebraska-Lincoln, inewman1@unl.edu \\ Duane F. Shell \\ University of Nebraska-Lincoln, dshell2@unl.edu \\ Linda J. Major \\ University of Nebraska-Lincoln, Imajor1@unl.edu \\ Thomas A. Workman \\ University of Nebraska-Lincoln
}

Follow this and additional works at: https://digitalcommons.unl.edu/edpsychpapers

Part of the Educational Psychology Commons

Newman, Ian; Shell, Duane F.; Major, Linda J.; and Workman, Thomas A., "Use of policy, education, and enforcement to reduce binge drinking among university students: The NU Directions project" (2006). Educational Psychology Papers and Publications. 111.

https://digitalcommons.unl.edu/edpsychpapers/111

This Article is brought to you for free and open access by the Educational Psychology, Department of at DigitalCommons@University of Nebraska - Lincoln. It has been accepted for inclusion in Educational Psychology Papers and Publications by an authorized administrator of DigitalCommons@University of Nebraska - Lincoln. 
Published in International Journal of Drug Policy 17 (2006), pp. 339-349; doi: 10.1016/j.drugpo.2006.01.005

Copyright $\odot 2006$ Elsevier B.V. http://www.sciencedirect.com Used by permission.

Submitted October 11, 2005; revised December 16, 2005; accepted January 6, 2006.

\title{
Use of policy, education, and enforcement to reduce binge drinking among university students: The NU Directions project
}

\author{
Ian M. Newman, ${ }^{1}$ Duane F. Shell, ${ }^{1}$ Linda J. Major, ${ }^{2}$ and Thomas A. Workman ${ }^{2}$ \\ 1. Department of Educational Psychology, University of Nebraska-Lincoln, PO Box 880345, Lincoln, NE 68588-0345 USA \\ 2. The Office of Student Involvement, University of Nebraska-Lincoln, PO Box 880345, Lincoln, NE 68588-0345 USA \\ Corresponding author - I. M. Newman, inewman1@unl.edu
}

\begin{abstract}
This paper describes a program, conducted over a 5-year period, that effectively reduced heavy drinking and alcoholrelated harms among university students. The program was organized around strategies to change the environment in which binge drinking occurred and involved input and cooperation from officials and students of the university, representatives from the city and the neighborhood near the university, law enforcement, as well as public health and medical officials. In 1997, $62.5 \%$ of the university's approximately 16,000 undergraduate student population reported binge drinking. This rate had dropped to $47 \%$ in 2003. Similar reductions were found in both self-reported primary and secondary harms related to alcohol consumption.
\end{abstract}

Keywords: college drinking, young adults, intervention programs, environmental management strategies, United States

In the United States (US), two out of every three full time college students report having drunk alcohol in the last 30 days. Problematic drinking is typically defined as drinking five or more drinks in a row on a single drinking occasion within the previous 2 weeks. Such drinking has been described as "binge drinking" by Wechsler, Austin, and Schuckit (1998) and as "heavy drinking" by O'Malley and Johnston (2002). A recent review of college student drinking rates-including data collected for the College Alcohol Study (CAS) conducted by the Harvard School of Public Health; The Core Institute's (CORE) Alcohol and Drug Survey conducted by Southern Illinois University; Monitoring the Future (MTF) conducted by the University of Michigan; and the National College Health Risk Behavior Survey (NCHRBS) conducted by the U.S. Centers for Disease Control and Prevention - found that approximately two of every five American college students can be termed "binge drinkers" (Wechsler et al., 1998). The consistency of these various estimates suggests considerable validity to the conclusion that about $40 \%$ of those students who drink alcohol are doing so in a manner that puts themselves and others at risk for physical, emotional, academic, and legal harms.
This level of binge drinking has been evident for some time. Wechsler et al. (2002) reported little overall change in drinking behavior and harms between 1993 and 2001. In the same period, harms experienced by drinkers did not decrease and, in some cases, showed slight increases. Harms experienced by students as the result of others' drinking stayed constant.

This paper describes the effectiveness of a campus/community coalition that sought to reduce binge drinking and related harms among a sample of university students. The university was the Lincoln campus of the University of Nebraska (UNL), and the coalition was known by its program name, NU Directions (pronounced as "new directions").

\section{The campus/community coalition reduce binge drink- ing and related harms}

Formed in 1998 as part of the A Matter of Degree (AMOD) program funded by the Robert Wood Johnson Foundation (RWJF), the NU Directions coalition involved a wide variety of partners from both the campus and community, co-chaired by the City of Lincoln chief 
of police and UNL's vice chancellor for student affairs. Community representatives included the City Council, the mayor's office, the local hospitality industry, city and county police agencies, state government, local prevention organizations, the city/county medical society, and various community organizations. Campus representatives included participants from student housing, Greek Affairs, ${ }^{*}$ the health center, the student judicial office, the vice chancellor for students, the parents association, athletics, and student government. Coalition membership has remained at approximately 40 members. Public commitments in support of the coalition have been given by past and present University of Nebraska-Lincoln chancellors and City of Lincoln mayors. Both UNL and the city have provided resources for several coalition projects to ensure their ongoing implementation.

The coalition spent approximately a year developing a comprehensive strategic plan based on a needs assessment, which incorporated local student behavioral and attitudinal data, as well as a thorough scan of the local environment. Approximately 70 partners from across the community and campus participated in the environmental scanning and strategic planning process. The coalition reviewed data collected from the Harvard College Alcohol Study and the Omnibus Survey on Student Life, conducted by UNL's Bureau of Sociological Research, which provided baseline data for student behavior. They also reviewed a variety of other indicator data, such as "last drink" reports from the detox facility (a quasi-medical, protective-custody facility for temporarily holding adults who are intoxicated to the degree that they need observation but not immediate medical care; staff members question detox clients about their drinking behaviors, including where they were served their last drink before police brought them to the detox facility), police arrest records, police calls for service, and citizen complaints. Finally, the group explored best practices and theoretical models from the national alcohol and other drug literature.

Basic to the strategic planning process was the agreement across the coalition on general philosophies that guided the activities of NU Directions and were consistent with the intent of the AMOD grant and RWJF. The coalition agreed to: (1) focus efforts toward harm reduction, seeking to reduce the incidence of high-risk (or "binge") drinking among UNL students; (2) view highrisk drinking as a shared responsibility of campus and community, rather than seeing it simply as the responsibility of the alcohol producer, seller, or consumer; (3) utilize an inclusive process where all stakeholders, regardless of interest, are invited to discussion and collaboration to solve alcohol-related problems; and (4) take a comprehensive approach that incorporated both individual and environmental strategies.

\footnotetext{
* Fraternities and sororities are private organizations for housing university students. A house council chooses members through an application and screening process. The houses are identified by Greek letters, and their members are known on campus as "Greeks."
}

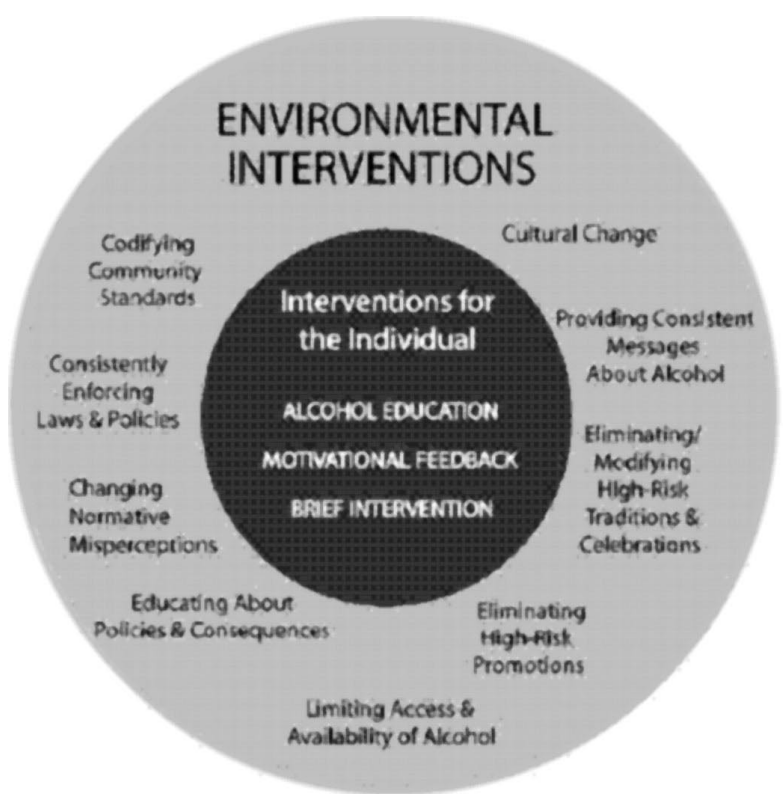

Figure 1. Model of comprehensive strategy for NU Directions

Using current theory and research in the environmental model, along with promising research in social norms and brief alcohol interventions (DeJong et al., 1998: Perkins, 2003), the coalition adopted a strategic model that incorporated measures targeting individuals, the campus, and the community (see Figure 1). Using the Precede-Proceed Model of Health Program Planning \& Evaluation (Green \& Kreuter, 2005), a comprehensive plan of 13 goals and 60 objectives that incorporated strategies designed to impact individuals, the campus, and the community was developed by NU Directions to accomplish the mission of the coalition. A set of measurable objectives was identified for each goal. Four workgroups organized around key areas of the strategic plan (policy and enforcement, social environment, neighborhood relations, and education) were formed by community and campus coalition members to identify activities that would accomplish each objective. Coalition members were able to self-select their workgroup based on expertise, interest, and potential contribution. An activities timeline was developed to assist the workgroups in the prioritization and timing of strategic implementation and to establish the length of each intervention. Workgroups met regularly throughout the project to implement activities and monitor their progress.

Whenever possible, coalition membership remained fluid to allow for the inclusion of new partners for specific objectives. Likewise, special task forces or project groups were formed for those activities that required additional partners, resources, or expertise. Examples of such groups included a task force of landlords to create model lease agreements; a committee of hospitality owners and managers to discuss a mandatory server training policy (and a subsequent steering committee to create a Web-based training program based on the committee's 
recommendations); and a task force of parents, bar owners, and students to address "birthday bar crawl" (Nebraska law requires a person to be 21 years old to purchase and consume alcohol or to enter establishments where alcohol is being served; this has led to the "birthday bar crawl" tradition in which a person celebrates his or her 21st birthday by going from tavern to tavern and drinking with friends throughout the night).

Students were involved throughout the process. A Student Advisory Group was formed through the first 2 years of the coalition to provide feedback on coalition plans and activities and to build student support for coalition initiatives. Whenever possible, academic classes were solicited to utilize a coalition objective or activity as a class project. Students from the College of Journalism and Mass Communication, the College of Arts and Sciences, College of Education and Human Sciences, and the College of Business Administration worked with NU Directions staff and workgroups on special projects, resulting in considerable student input and collaboration. Student representatives from student government, athletics, fraternities and sororities, the Peer Alcohol Education Group, and residence hall government were placed in every workgroup.

Although not explicitly used during intervention planning, the NU Directions initiatives reflected principles of social cognitive theory (SCT) (Bandura, 1986, 2001, 2004; Zimmerman, 2004). From a SCT perspective, alcohol use is influenced by a triadic reciprocal relationship between the environment, the person, and the person's behavior within the environment. The environment provides the context for possible alcohol use, including the legal and policy regulations surrounding use (e.g., whether alcohol is available, the consequences of alcohol misuse, and so on). A person's knowledge and beliefs about alcohol and alcohol use provide motivations to drink or not to drink, including outcome expectancies (what the person expects will happen if he or she drinks or does not drink, and why), self-efficacy (the person's confidence in his or her abilities to resist or control alcohol consumption), knowledge of laws and policies, and internalized socio-cultural norms about drinking. A person's actions of drinking or not drinking both influence the environment that individual experiences (e.g., choosing to be in environments where alcohol is available rather than those where it is not available or choosing to associate with peers who drink) and result in consequences (rewards and punishments) that affect a person's knowledge and beliefs. These triadic reciprocal determinants were accommodated in the NU Directions strategic model, shown in Figure 2.

The model focused efforts on development of a coordinated intervention approach to address the environment through three primary mechanisms: policy, education, and enforcement. Policies adopted by the campus, community, or state through NU Directions initiatives

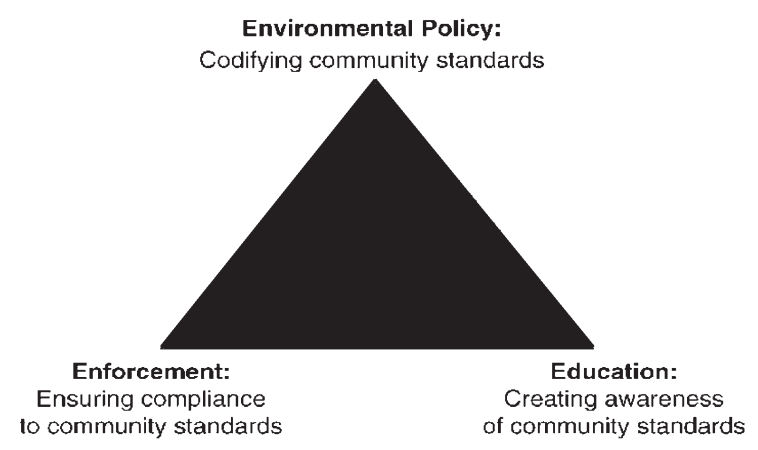

Figure 2. NU Directions strategic model for addressing environmental elements.

included the use of plans to eliminate alcohol use in fraternity and sorority dwellings as a condition of university housing status, the use of last drink data in determining "problem" establishments near the campus, conditions on alcohol license application approvals for "high-risk" establishments, and the adoption of state legislation enabling a secure digital driver's license system. The University of Nebraska-Lincoln had policies in place that restricted alcohol in student residences, sales of alcohol on campus, and sponsorship of athletic events by alcohol producers prior to NU Directions. Education efforts included social marketing campaigns aimed at first-year students and other high-risk populations. The initiatives explained current policies and consequences of campus drinking and facilitated the creation of a web-based responsible alcohol server training program across the state of Nebraska and of community forums to educate special populations on how to avoid highrisk practices that are contrary to policy. Education on alcohol policies was included into the orientation sessions for new students. Enforcement: since the creation of the NU Directions coalition, both campus and community enforcement of alcohol policies and ordinances have increased.

\section{Individual interventions}

In this paper, we are reporting mainly on how to use policy, education, and enforcement to change the environment in which high-risk college drinking occurred. In addition to environmental changes, the NU Directions coalition also instituted interventions that addressed the attitudes and behaviors of individual students, particularly of those in high-risk populations. These efforts included using brief intervention/motivational feedback mechanisms, such as the Alcohol Skills Training Program (ASTP), Brief Alcohol Screening and Intervention for College Students (BASICS), and Check-Up to Go, a paper/web feedback program. Students were enrolled in these programs through sanctions from judicial affairs or through fraternity/sorority leadership and athletic team managers. 


\section{Communications campaigns}

The NU Directions staff member who had expertise in communications assisted in developing and enacting the advocacy, education, social norms, and social marketing activities of the strategic plan. Media advocacy was utilized to raise community awareness and support or political pressure where program objectives required the community to enact supportive policy. Media coverage of coalition activities and successes was consistently solicited to educate the community about environmental contributors to college drinking problems. Social marketing and social norms campaigns were implemented as directed by the coalition's strategic plan both on campus and in the community to assist in changing the culture of college drinking.

\section{Why an environmental approach?}

Environmental approaches have been recommended by the US Department of Education's Higher Education Center for Alcohol and Other Drug Prevention as the preferred philosophy for campus alcohol intervention (DeJong et al., 1998). Research has found that interventions directed at environmental factors have an impact on drinking and harms. Buka and Birdthistle (1999) found that implementation of community-wide server education impacted server practices for as long as 4 years. Cohen and Rogers (1997) found that changing policy enforcement and sanctions on a university campus resulted in an increase in overall violations but a decrease in serious violations and repeat offenders. Lewis et al. (1996) found that having adults and minors issue informal "citations" to clerks willing to sell to minors and providing commendations to those who refused reduced sales to underage individuals. Johannessen, Glider, Collins, Hueston, and DeJong (2001) found decreases in alcohol sales and neighborhood complaints and increases in availability of non-alcoholic alternatives, food, and ID checking after new policies and enforcement for alcohol control at homecoming were implemented. In evaluating the AMOD program, the most ambitious project to support implementation of an environmental approach on college campuses, Weitzman, Nelson, Lee, and Wechsler (2004) found that campuses that implemented a higher number of environmental strategies had significant reductions in high-risk drinking, drinking-related harms, and harms experienced by students as a result of others' drinking, relative to campuses with a lower number of implemented environmental strategies.

\section{Methods}

Baseline data were obtained from an environmental scan that included information on existing alcohol laws and policies at the campus, community, and state levels; outlet density; enforcement practices on campus and in the community; pricing, advertising, and promotions at local establishments; and existing community and campus alcohol efforts. As part of the evaluation, overseen by the Harvard School of Public Health, data were collected annually on state, city, and campus law and policy changes, campus and community police arrest data, campus alcohol sanction data, community hospital and emergency ICD-9 alcohol discharge data, protective custody transports to detox, and tracking of liquor licenses. In addition, monthly tracking of campus and city newspaper advertising and tri-annual tracking of on- and offsale window advertising was done. Specific coding policies for annual indicator data tracking were developed by the Harvard School of Public Health.

\section{Data source}

The primary data source for determining changes in students' drinking behaviors and harms was the College Alcohol Study (CAS). The CAS, conducted by the Harvard School of Public Health, was a national mail survey of college students, which measured drinking patterns and consequences of alcohol consumption. Random samples of students at UNL were first surveyed in 1997 and then annually from 1999 to 2003. Demographics of the samples are provided in Table 1. All samples were weighted to actual UNL demographics in the baseline year. CAS data from 1997 provided a baseline and was a key source for identifying needs and outcome targets for the initial NU Directions RWJF grant. Analysis of statistical significance for time series changes in CAS data were done by the Harvard School of Public Health as described in Weitzman et al. (2004). In addition to CAS, data from the UNL Omnibus survey, a telephone survey of UNL students conducted for the vice chancellor of student affairs, was used to supplement CAS for program planning and outcome evaluation.

Table 1. Sample demographics

\begin{tabular}{lcccccc}
\hline & 1997 & 1999 & 2000 & 2001 & 2002 & 2003 \\
\hline Percentage of male & 46.3 & 45.2 & 47.2 & 46.4 & 46.3 & 47.0 \\
Percentage of white & 92.6 & 90.5 & 92.2 & 93.1 & 93.0 & 86.0 \\
Percentage of 23 years and younger & 91.2 & 90.7 & 88.6 & 94.0 & 92.3 & 89.4 \\
Percentage of member fraternity/sorority & 26.8 & 21.0 & 23.3 & 22.2 & 18.6 & 16.3 \\
Percentage of who live off campus & 51.0 & 52.3 & 69.7 & 52.5 & 51.7 & 48.6 \\
Response rate & 68.0 & 62.0 & 58.0 & 63.0 & 49.0 & 55.0 \\
Sample size & 435 & 388 & 378 & 366 & 362 & 388 \\
\hline
\end{tabular}




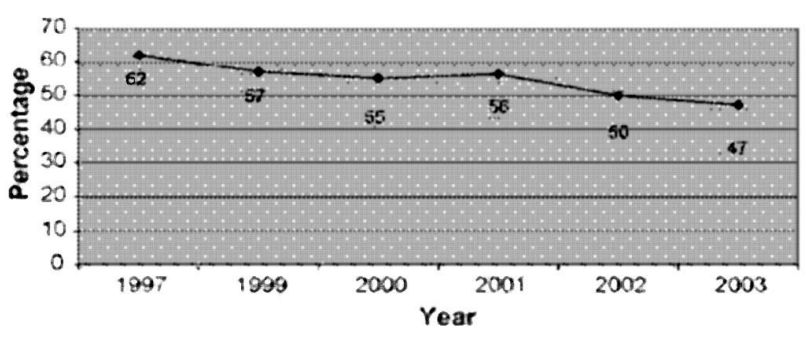

Figure 3. Change in student binge drinking.

\section{Results}

Program interventions were expected to alter the environment -including access to and availability of alcohol, price, promotions, advertising, and socio-cultural climate-in ways that produce changes in policy, enforcement, and entertainment practices (Level 1). Level 1 environmental changes were expected to lead to changes in alcohol availability and student norms and perceptions about appropriate alcohol use (Level 2). Level 2 changes were expected to result in changes in drinking behavior and reduction in harms (Level 3).

\section{Changes in drinking behaviors}

Figure 3 shows the overall binge drinking rate (five or more drinks for men and four or more drinks for women per drinking session) across all survey years. The percentage of UNL students who binged on at least one occasion in the past 2 weeks dropped from $62 \%$ in 1997 to $47 \%$ in 2003 . This $15 \%$ change was statistically significant. These trends are further substantiated by examining changes across time in the average number of drinks per occasion. Figure 4 shows an increase in students who reported drinking four or fewer drinks, and a decrease in those who reported drinking five or six drinks - while the number of students reporting drinking seven or more drinks has stayed relatively constant. This suggests that reductions in binge drinking have occurred primarily by making moderate or borderline

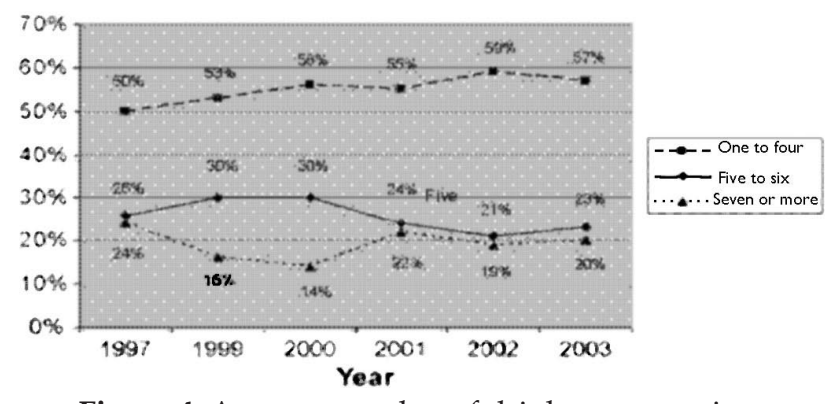

Figure 4. Average number of drinks per occasion.

high-risk drinkers more moderate, rather than by reducing the drinking of high-risk frequent binge drinkers.

In addition to binge and other high-risk drinking, NU Directions placed considerable emphasis on reducing harms associated with drinking. There was a statistically significant decrease in the alcohol-related problems experienced by UNL students since NU Directions began (see Table 3). NU Directions focused on creating an environment conducive to studying and academics and on reducing personal alcohol-related harms. During the program, students showed significant decreases in missing a class or getting behind in schoolwork as a result of drinking, with students reporting these problems less than half as much in 2003 as in 1997. Students reported significantly fewer alcohol-related instances of doing something they regretted, having blackouts, or arguing with friends. Although fewer students reported engaging in unplanned or unprotected sex in 2003 relative to 1997, the difference was not statistically significant. Perhaps the most impressive change was a more than $50 \%$ decrease in students reporting five or more of these problems.

Figure 5 shows that there was little change in students' reported drinking and driving during the early years of the project. However, drinking and driving began to decrease in 2002. By 2003, a significantly lower percentage of students reported driving after drinking, driving after binging, and riding with a driver who was high or drunk. Although these decreases are encouraging, especially for driving after 5 or more drinks, the

Table 2. Problems reported by students who drank alcohol in the past year

\begin{tabular}{|c|c|c|c|c|c|c|}
\hline \multicolumn{7}{|l|}{ Drinking has caused you to } \\
\hline Miss a class ${ }^{a}$ & 46.2 & 38.5 & 27.0 & 33.3 & 31.7 & 24.8 \\
\hline Do something you regret ${ }^{a}$ & 48.9 & 46.4 & 38.3 & 47.7 & 39.5 & 33.2 \\
\hline Forget where you were/what you did ${ }^{a}$ & 36.5 & 35.8 & 30.6 & 31.7 & 29.5 & 26.3 \\
\hline Argue with friends ${ }^{a}$ & 37.5 & 30.2 & 25.4 & 29.1 & 27.3 & 22.9 \\
\hline \multicolumn{7}{|l|}{ Have five or more problems ${ }^{a}$ (excluding } \\
\hline hangover; including drinking and driving) & 34.2 & 28.3 & 20.7 & 25.8 & 25.4 & 14.9 \\
\hline
\end{tabular}

${ }^{a}$ Change is statistically significant, $p<.05$ 


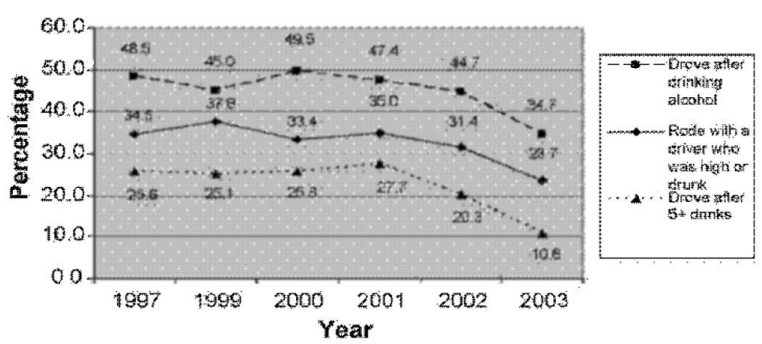

Figure 5. Patterns of student drinking and driving.

rates of drinking and driving remained high, particularly among high-risk drinkers. About $65 \%$ of frequent binge drinkers and $43 \%$ of occasional binge drinkers reported drinking and driving, compared to only $26 \%$ among those who drink but do not binge.

NU Directions focused on reducing secondary effects of drinking - that is, problems students experience from other students' drinking, particularly behaviors that interfere with studying and getting sufficient sleep. There was a large and statistically significant decrease in the secondary effects of drinking experienced by students (see Table 3). The percentage of students who reported being insulted dropped by almost one-half and student reports of arguments or having their property damaged by intoxicated peers decreased by about one-third. There was no change in students who reported being assaulted, although this occurred to only a small proportion of students in any year. In relation to their sleep and study environment, about $20 \%$ fewer students reported having to "baby sit" a fellow student in 2003 relative to 1997; however, there was no change in students who reported having their sleep or study interrupted - a problem reported by over half the students in any year. About one-third fewer students reported an unwanted sexual advance, and about two-thirds fewer students reported a sexual assault.

\section{Policy, education, and enforcement in producing change in drinking and harms}

SCT proposes that the modifications in drinking and harms found during the course of NU Directions result from reciprocal influences of change in the environment: shifts in policy, in consequences of drinking behavior due to increased enforcement, and in students' knowledge and perceptions of the environment and enforcement.

The alcohol policies of the city and the university, in principle, could not he clearer. Alcohol consumption is not allowed on any government-owned property, including streets, sidewalks, parks, and all university land and buildings. These policies, however, are not absolute. The university often allows alcohol in campus facilities through a special permit process. The city also allows alcohol on public property for events and festivals through a special designated license.

Students had long flouted university policy by smuggling alcohol into their campus residences, even at the risk of being fined or arrested. Students and adult sport fans regularly smuggled alcohol into university sporting events, although a ban on bringing in coolers and large containers had cut gross abuse. Tailgate parties (pre- and post-game parties in parking lots) with alcohol were prevalent, even in the university and city parking lots where alcohol is prohibited.

Perhaps the policy that affects university students the most is the minimum drinking age law. A person must he 21 years old to purchase or consume alcohol or to enter taverns where alcohol is being served. In the US, most students enter university around age 18 to study for 4 years, meaning that they are too young to legally purchase and consume alcohol for the first 2 or 3 years of their university career. Students developed several ways of getting around this law, most commonly by asking an older person to buy alcohol for them or by purchasing a forged driver's license with a false birth date.

\section{Change in the policy environment affecting alcohol use during NU Directions}

Though the alcohol policy environment in the community and on campus at the start of the grant already discouraged high-risk and underage drinking, NU Directions engaged in specific initiatives to help remediate policy deficiencies.

Due to conditions of the grant, NU Directions members could not directly lobby for state law changes, so they undertook a number of strategies to support state law changes. Each year at the start of the legislative session, a coalition meeting was devoted to review all al-

Table 3. Students bothered by others' drinking (secondary effects of drinking)

\begin{tabular}{|c|c|c|c|c|c|c|}
\hline Students bothered by others' drinking & 1997 & 1999 & 2000 & 2001 & 2002 & 2003 \\
\hline Had a serious argument or quarrel ${ }^{\mathrm{a}}$ & 35.5 & 34.4 & 25.6 & 31.6 & 28.9 & 22.5 \\
\hline Had property damaged ${ }^{\mathrm{a}}$ & 18.5 & 17.8 & 16.5 & 12.1 & 17.9 & 12.2 \\
\hline Had to "baby sit" a drunken student ${ }^{\mathrm{a}}$ & 66.0 & 63.4 & 56.7 & 54.7 & 59.2 & 53.3 \\
\hline Had studying/sleep interrupted & 58.7 & 56.9 & 50.4 & 51.1 & 49.6 & 51.8 \\
\hline
\end{tabular}

${ }^{a}$ Change is statistically significant, $p<.05$ 
cohol-related legislation and to determine which bills coalition members would support or oppose. NU Directions would then supply data and interpretation to those coalition members and organizations who could take a more direct role in lobbying. In 1999, with the support from NU Directions, the legislature approved a graduated driver's license for youth. In 2000, having an open alcohol container in a motor vehicle and an open alcohol container in public were made an offense. In 2001, the legal limit on blood alcohol content for operating a motor vehicle was lowered from. 10 to .08 , and alcohol consumption (in addition to possession) by a person younger than age 21 was made an offense. In 2000, NU Directions hosted a False ID community forum to address issues surrounding false IDs. Following the forum, the Director of the Department of Motor Vehicles changed the state policy to prohibit persons from having both a driver's license and state ID; in 2001, the State Legislature passed a law requiring a new digital driver's license that makes forgery difficult. These new laws strengthened the policy and enforcement environment.

As a result of state law and State Supreme Court decisions in the late 1980s and early 1990s, virtually all control of alcohol licensing and regulation resided in the State Liquor Control Commission. NU Directions undertook initiatives to try to influence and alter Liquor Control Commission policies. In 2000, NU Directions held a two-part state-wide symposium on utilizing local controls to address alcohol concerns; in 2002, it facilitated a round-table involving police, city officials, Liquor Control Commission prosecutors, and NU Directions and community members to explore ways to reduce "overservice." The Liquor Control Commission funded NU Directions' development of a Web-based server training program and made it available state-wide.

On the city level, NU Directions has provided significant input to the Lincoln City Council through the council's internal liquor committee. In the fall 2000, NU Directions used GIS data to show alcohol-related problems in the downtown area near campus, leading to the establishment of an internal liquor committee workgroup to examine conditional use permits. Since 2001, NU Directions has researched zoning options and shared the results with the City Council Internal Liquor Committee. In 2003, NU Directions was asked to provide an analysis of high-risk establishments and make recommendations for a new conditional licensing policy. Using environmental indicator data and on-site observations in bars, a report was prepared that associated a high proportion of problems with establishments that only served alcohol (alcohol only, no food service) and those with only limited food services. This led to a recommendation to place special conditions, including increased levels of mandatory server training and minimum staff-to-patron ratios, on these establishments.

In 2001, the Nebraska Supreme Court upheld the City of Lincoln's denial of an off-sale liquor license for failure to comply with local zoning regulations. This ruling re- versed the rulings of the late 1980s and early 1990s, and allowed the city to pursue zoning as a means to control licensing. After the ruling, the City of Lincoln, using data provided by NU Directions, began a number of specific policy and enforcement actions. In 2002, the City Council adopted a formal internal policy for approving special use permits. Also in 2002, the city took the first action to add conditions to a liquor license requested by a dance club. The State Liquor Control Commission did not contest the conditional license, thus establishing a precedent for local jurisdictions over license conditions.

Because the university campus was basically "dry" prior to NU Directions, there were no significant changes in the formal policy environment at the university level. The most significant attempts to address the alcohol environment on campus centered on the Greek system (fraternities and sororities). Although drinking already was not allowed in fraternity or sorority living units, a number of alcohol-related incidents had occurred in Greek houses throughout the 1990s. NU Directions made efforts to address Greek drinking beyond enforcement and sanctioning. These efforts began as educational/ informational activities and then developed to address risk-management issues. Specific efforts facilitated by NU Directions included the following: (1) in 2000, NU Directions and Greek Affairs hosted a 1-day alcohol summit for Greek leaders and students concerning alcohol and other risk management issues; (2) in 2002, UNL fraternity and sorority leaders sponsored a risk management summit, and a Risk Management Guide for Alcohol was developed and distributed; (3) in 2002, the InterFraternity Council created an Ethics Committee with the goal of using peer pressure by fraternity leaders to help fraternities address high-risk activities, including alcohol-related issues; (4) in spring 2002, the Inter-Fraternity Council developed the NU Greek program to provide certification to chapters that meet specific guidelines in the areas of social activities, risk management, chapter programming, judicial affairs, and alumni events; and (5) in 2003, the University received a 2-year US Department of Education Grant to establish the Greek ReEvolution program to comprehensively address Greek life (including alcohol issues) by emphasizing non-alcohol aspects of Greek living and culture.

\section{Change in enforcement of alcohol policies and laws}

As noted previously, alcohol laws and policies were regularly ignored or circumvented by students and others in the community. Because of this, a significant focus of NU Directions was on increasing the enforcement and consistency of enforcement on campus and in the community.

At the community level, the NU Directions coalition provided advocacy and public support for increased policing efforts, especially for driving under the influence (DUI) and minor in possession (MIP) offences. The coalition also backed efforts to increase enforcement for forged drivers' licenses, over-service, and other liquor law violations. 


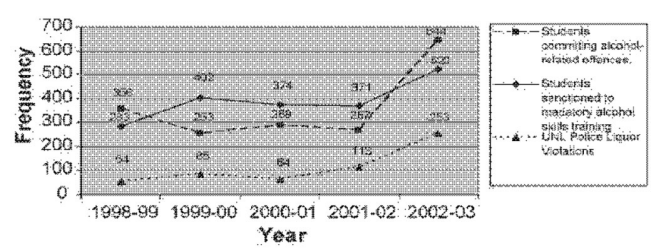

Figure 6. Trends in campus alcohol-related citations and sanctions.

NU Directions assisted community policing by providing funding for a "Wild Party Patrol" to police large parties on certain weekends throughout the year.

The results of increased enforcement can he seen in community police arrest statistics. Arrests for liquor law violations (MIP, public consumption, false ID, and establishment violations) increased from 1,317 in 1997 to 3,110 in 2003. In areas targeted by NU Directions, MIP arrests increased from 667 in 1997 to 1,434 in 2003, and disorderly house (Wild Party Patrol citations) increased from 207 in 1997 to 550 in 2003. The only arrest statistic that did not substantially change was DUI, with only a moderate increase from 1,143 in 1997 to 1,345 in 2003, although a peak of 1,605 arrests in 1999 during NU Directions' first year may have helped reduce drinking and driving in subsequent years. These statistics indicate a substantial increase in community enforcement during the NU Directions grant period.

At the university level, NU Directions supported efforts to enforce campus no-alcohol policies, especially in residences, in Greek houses, and at tailgate parties. Campus police citations for liquor violations increased slightly from 54 to 64 between 1998 and 2000. In 2001, the university hired a new police chief, who became an NU Directions coalition member. Thereafter, citations increased to 253 in 2002-2003 (see Figure 6). The number of students reported to the student judicial affairs office for alcohol-related offences increased from 356 in the 1998-1999 academic year to 644 in 2002-2003. The number of students sanctioned to mandatory skills training increased from 283 in 1998-1999 to 522 in 2002-2003. In 2002-2003, 11 of the 21 fraternities at UNL were being sanctioned by Student Judicial Affairs. These increases in citations and sanctions indicate a significant increase in campus alcohol enforcement during the NU Directions grant.

\section{Change in students' knowledge, perceptions, and norms}

In SCT, the impact of changes in the policy environment and enforcement related to drinking behaviors is mediated through changes in students' perceptions and norms. Pursuant to its strategic model (see Figure 3 above), NU Directions attempted to educate students about coalition efforts, policy changes, and enforcement. On campus, this was achieved with the help of peer alcohol educators, billboards and media advertisements of campus norms, press conferences on police enforcement efforts, and a Web site. Specific educational campaigns were directed at entering first-year students and their parents.
In 2003, data from the CAS survey found that about 60 to $70 \%$ of students indicated receiving information about where to get help for alcohol-related problems, the dangers of alcohol overdose, UNL drinking rules, and penalties for breaking those rules. A somewhat smaller percentage of students (from 45 to $55 \%$ ) indicated getting information on long-term health effects of alcohol use and on recognizing another's problem drinking. Firstyear students reported receiving information at about $10 \%$ higher rates than the general student population. These percentages were about 10\% higher than in 1997. Although only asked from 2001 to 2003, an increasing percentage of students (from 60 to $70 \%$ ) indicated seeing information on student drinking norms. These data suggest that a majority of UNL students were exposed to relevant information about environmental changes.

\section{Discussion}

\section{Limitations of the results}

Results were not obtained from a true randomized controlled trial. Therefore, it is impossible to say with certainty that any of the observed changes in students' reported drinking and harms resulted from the work of NU Directions. Indirect comparison data, however, is available. National College Alcohol Study surveys conducted by Harvard School of Public Health did not find any general changes in college drinking and harms from 1993 through 2001 (Wechsler et al., 2002). The National College Health Assessment (American College Health Association, 2005), the only published national survey data through 2003, reported similar drinking and harm levels to the previous National College Health Risk Behavior Survey in 1995 (Douglas et al., 1997). These studies suggest that, in general, there has not been any decrease in drinking among college students corresponding to those found at UNL during the time that NU Directions has been functioning. Weitzman and colleagues (2004) found that projects in the AMOD program (including NU Directions) that implemented a higher number of environmental strategies had greater reductions in students' drinking and harms than either AMOD projects that did not implement as many environmental strategies or a comparison sample of colleges and universities surveyed as part of the College Alcohol Survey. Also, the largest changes in student drinking and harms came in 2002 and 2003, after the majority of NU Directions interventions and activities had been implemented and enforcement changes had occurred. The indirect comparison data and correspondence between NU Directions activities and change suggest that at least some, if not most, of the changes in UNL students' drinking and harms can he reasonably attributed to activities initiated through NU Directions. The lag between implementation of activities and measured changes in behaviors seemed to fit the pattern proposed by diffusion theory (Rogers, 2003). 


\section{Suggested reasons for success of NU Directions}

In retrospect, it is useful to examine why this community organizing effort was apparently successful, and why the coalition stayed together and stayed on task. From a policy perspective, a number of important lessons can be highlighted.

\section{Coalition staff understood community organizing}

The key staff person in the coalition had a clear understanding of the local politics, history, barriers, and incentives of those who worked in the community. The ability of the coalition leadership to identify and understand this changing political climate was critical to the coalition's success. Also critical was the understanding of the need for all stakeholders to have a place at the table, regardless of their initial position on the issue of high-risk drinking. Savvy leadership shaped the coalition's character by deciding that not everyone on a coalition had to have the same role or level of involvement. Some members served continuously, while others served on a "will call" basis, summoned when their expertise, influence, or experience was needed. In this way, the coalition captured the full resources of the community.

\section{The focus remained on dialogue between stakeholders}

In many ways, simply raising awareness and beginning public dialogue about an issue effected change. Communication within the coalition was, in fact, a key part of the strategic planning process for effecting change. Outside the coalition, strategic communications directed at target audiences with carefully selected channels, spokespersons, and timing created the type of public dialogue that affected change. Given the natural resistance of humans to change, soliciting feedback from all stakeholders was essential; therefore, before embarking on a project, the coalition or its partners held community forums to raise the issues, solicit reactions, and identify barriers and opportunities. Feedback was also solicited formally through surveys, focus groups, and polls-and informally through conversations, editorials, letters to the editor, and discussion groups. Negative feedback was used to identify misunderstandings, locate key issues and barriers, and open opportunities for building trust and respect.

Because communities are comprised of individuals who live and act on their own value and belief systems, each deserves to he understood and respected. For example, limiting access and encouraging reduction and use of alcohol by students of legal drinking age has a potential impact on those trying to make a living running bars and restaurants. For these business people, the prospect of increased controls presents a threat to their business and family livelihood. Understanding this perspective helps coalition members to seek more creative ways to help bar owners become more successful, while maintaining community standards.
Many community decisions are made behind closed doors, in non-public forums. Because of this, coalition staff members needed to work to he "at the table" for community discussions and, when this was not possible, to use coalition members who were already at the table to ensure that the coalition's objectives are clearly presented and understood, and that possible opposition is identified and communicated to the core planning group.

\section{Commitment to the environmental approach}

The entire coalition, its members and staff, embraced the environmental approach. Because there is always a strong tendency in alcohol education/harm reduction programs to focus on specific program strategies rather than on the broader environmental management approach, it was critical for the core planning group to share a strong common commitment to the environmental approach.

\section{Commitment to environmental scanning}

Knowledge of the environment was essential. Strategic planning began with a careful assessment of the local conditions and the alcohol environment, the identification of environmental factors needing change, and the evaluation of existing programs and services across the campus and community. It was also important to assess the capacity of the community to adopt the proposed changes. This coalition spent an entire year collecting and discussing data, hearing from various stakeholders, and discussing the political, social, philosophical, and economic realities of the university and the community. The coalition also reviewed research from a variety of fields related to community alcohol problems.

\section{To accommodate the fluid environment, strategic plans were flexible}

Even the best strategic plans cannot guard against discoveries of new barriers, challenges, and environmental factors. A good example of this was the coalition's attempt to incorporate conditional use permits into the city's alcohol license approval policy. The coalition followed a strategic long-term course to introduce this concept through expert testimony and to create support for the City Council's action. At a public meeting designed to encourage support, significant resistance developed. Ultimately, this objective had to he reconceived to accommodate the political will of the community.

\section{Coalition members captured all opportunities}

Some of the greatest opportunities to advance the agendas to reduce high-risk drinking arose unexpectedly. For example, at a meeting of the City Council's Internal Liquor Committee, the NU Directions project director was able to offer coalition assistance and information on several occasions and, in so doing, provide insight for the 
committee into the issues and concerns of the university and its students. The result was a rapid advancement of coalition goals and a sense of gratitude rather than pressure from the community leaders.

\section{Communications were critical}

Establishing the coalition's presence in the community required the full-time support of a communications specialist. The communications challenge was multifaceted. The communications plan needed to be both proactive, promoting the need for the program and proposing solutions to the community, and reactive, responding to misperceptions and criticisms by stakeholders who were impacted by the resultant changes. Local media, like national media, were highly influenced by reports highlighting the problem of binge drinking and often framed efforts of the campus community coalition in a war analogy, where administrators and police "battle" students over their drinking behavior. Media reports of coalition efforts were sometimes presented against a backdrop of crowded bar scenes and irresponsible drinking. To counter, the coalition provided sound-bites and strong visuals to overcome the superficial portrayal of college binge drinking problems. Whenever possible, multiple spokespersons representing a variety of interests and community positions were provided to the media.

Because coalition members had varied experiences with and perspectives on the issue of binge drinking, care was taken to ensure that messages about the coalition goals and activities were uniform and consistent. Clear and concise messages were developed and distributed, and spokespersons were carefully selected and well-trained. Many NU Directions members wanted to know how to put the message of the coalition into a context that made sense to them and to the stakeholders they represented.

\section{The coalition often highlighted positive changes}

The coalition did not assume that positive contributions were recognized by the general public, and it found itself constantly battling an overarching theme that the effort was hopeless. The coalition recognized the need to promote the successes of its work by taking every opportunity to highlight positive changes to the campus community and the larger community through the media or through presentations to important groups.

\section{An environmental approach is a process, not a strategy}

Implementation of an environmental approach should focus on process and not on imitating a specific list of strategies. The specific interventions and approaches undertaken by NU Directions reflect the local environment-the city of Lincoln and UNL. These conditions are unlikely to he exactly duplicated in other places. However, the process NU Directions used in creating a local coalition to build goals, objectives, and activities, utilizing local data and indicators to identify strategies that would meet local needs, can be replicated. This process, not the actual strategies pursued, is the key to successful implementation of an environmental approach.

\section{Acknowledgments}

Funding for this program came from The Robert Wood Johnson Foundation (US). The authors acknowledge the assistance provided by Michelle Maas in preparing this article.

\section{References}

American College Health Association (2005) The American College Health Association National College Health Assessment (ACHA-NCHA), Spring 2003 Reference Group Report. Journal of American College Health, 53, 199-210.

Bandura, A. (1986) Social foundations of thought and action: A social cognitive theory. Englewood Cliffs, NJ: Prentice-Hall.

Bandura, A. (2001) Social cognitive theory: An agentic perspective. Annual Review of Psychology, 52, 1-26.

Bandura, A. (2004) Health promotion by social cognitive means. Health Education and Behavior, 31, 143-164.

Buka, S. L . \& Birdthistle, I. J. (1999) Long-term effects of a community-wide alcohol server training intervention. Journal of Studies on Alcohol, 60, 27-36.

Cohen, F. \& Rogers, D. (1997) Effects of alcohol policy change. Journal of Alcohol and Drug Education, 42, 69-82.

DeJong, W., Vince-Whitman, C., Colthurst, T., Cretella, M., Gilbreath, M., Rosati, M., et al. (1998) Environmental management: A comprehensive strategy for reducing alcohol and other drug use on college campuses. Newton, MA: Higher Education Center for Alcohol and Other Drug Prevention.

Douglas, K. A., Collins, J. L., Warren, C., Kann, L., Gold, R., Clayton, S., et al. (1997) Results from the 1995 National College Risk Behavior Survey. Journal of American College Health, 46, 55-66.

Green, L. W., \& Kreuter, M. W. (2005) Health program planning: An educational and ecological approach (4th ed.). New York: McGraw Hill.

Johannessen, K., Glider, P., Collins, C., Hueston, H., \& DeJong, W. (2001) Preventing alcohol-related problems at the University of Arizona's homecoming: An environmental management case study. American Journal of Drug and Alcohol Abuse, 27, 587-597.

Lewis, R. K., Paine-Andrews, A., Fawcett, S. B., Francisco, V. T., Richter, K. P., Copple, B., et al. (1996) Evaluating the effects of a community coalition's efforts to reduce illegal sales of alcohol and tobacco products to minors. Journal of Community Health, 21, 429- 436.

O'Malley, P. M., \& Johnston, L. D. (2002) Epidemiology of alcohol and other drug use among American college students Journal of Studies on Alcohol, (Suppl. 14), 23-29.

Perkins, H. W., ed. (2003) The social norms approach to preventing 
school and college age substance abuse: A handbook for educators, counselors and clinicians. San Francisco: Jossey-Bass.

Rogers, E. M. (2003) Diffusion of innovations (5th ed.). London: Free Press.

Wechsler, H., Austin, S. B., \& Schuckit, M. A. (1998) Binge drinking: The four/five measure. Journal of Studies on Alcohol, 59, 122- 124.

Wechsler, H., Lee, J. E., Kuo, M., Seibring, M., Nelson, T. F., \& Lee, H. (2002) Trends in college binge drinking during a period of increased prevention efforts: Findings from 4 Harvard School of Public Health College Alcohol Study Surveys, 1993-2001. Journal of American College Health, 50, 203-21 7.
Weitzman, E. R., Nelson, T. F., Lee, H., \& Wechsler, H. (2004) Reducing drinking and related harms in college: Evaluation of the "A Matter of Degree" program American Journal of Preventive Medicine, 27, 187-196.

Zimmerman, B. J. (2004) Sociocultural influence and students' development of academic self-regulation: A social-cognitive perspective. In: D. M. McInerney \& S. van Etten, eds., Big theories revisited: Research on sociocultural influences on motivation and learning (pp. 139-164) Greenwich, CT: Information Age Publishing. 